\title{
EL MODERNISMO CONTRA LA NACIÓN. LA POLÉMICA LITERARIA DE 1894 EN COSTA RICA
}

\author{
Alexánder Sánchez Mora
}

\begin{abstract}
RESUMEN
La polémica literaria de 1894 en Costa Rica significó tanto un momento más dentro del accidentado proceso de recepción del modernismo en todo el ámbito hispanoamericano, como un desafío para el proyecto liberal de invención de la nacionalidad y la articulación de una identidad costarricense. El siguiente artículo busca, desde esta perspectiva, comprender las matrices discursivas enfrentadas en dicha polémica.
\end{abstract}

\begin{abstract}
The literary controversy of 1894 in Costa Rica became both one more moment in the eventful arrival of modernism in Latin American and a challenge for the liberal plan: to create the concept of nationality and to articulate the Costa Rican identity. From this perspective, the present article seeks to understand the discourse matrices represented in the aforementioned controversy.
\end{abstract}

\section{Héroes y villanos en la literatura costarricense}

El tratamiento que se ha dado a la polémica de 1894, luego continuada en 1900, entre modernismo y nacionalismo, entiéndase realismo, es un caso privilegiado para ejemplificar que tras la constitución del discurso literario existe todo un aparato institucional, prácticas discursivas y no discursivas, que determinan el funcionamiento de los textos (Trottier 1993: 40). Durante décadas, una historiografía literaria costarricense aquejada de nacionalismo le ha endilgado a Ricardo Fernández Guardia el papel del villano en esta polémica. Por el contrario, su oponente, Carlos Gagini, resulta adornado por cualidades extraliterarias que hacen de él una especie de héroe cívico dotado de particular lucidez y patriotismo.

Un rápido recorrido por algunos de los textos críticos más relevantes permite captar las coincidencias que devinieron en opinión generalizada y casi incuestionable. Fernández Guardia se convirtió en un individuo "deslumbrado por lo extraño" (Chase 1975: 23), que sostuvo durante la polémica una "tesis formal y académica" (Bonilla 1981: 111), que actuó con "la vehemencia de la juventud” y que atacó a su "país natal” (Castro Rawson 1966: 165) y cuya producción literaria, excluyendo sus crónicas históricas, es catalogada como "frutos anémicos y artificiales” (Quesada 1986: 102). En contraposición a tales juicios desaprobatorios, se afirma 
que Gagini tenía un panorama más amplio y profundo sobre las posibilidades de la literatura costarricense (Bonilla 1981: 111, Valdeperas 1991: 36), que su libro Chamarasca es de "sana intención nacionalista" y "enraizado en lo nuestro" (Chase 1975: 23) y que en la polémica defiende al pueblo costarricense de los ataques de Fernández Guardia (Castro Rawson 1966: 165).

Habría que esperar hasta la década de 1990 para que bajase la corriente condenatoria de las posiciones defendidas por Fernández Guardia. Estudios como los de Ovares et al (1993: 128-41), Barrantes (1997: 167-89), Rojas y Ovares (1995: 32-5) y Quesada (1998: 37-9) se distancian del enjuiciamiento ético-patriótico y consideran los textos de la polémica en cuanto prácticas discursivas en su especificidad histórica, de modo tal que han posibilitado el acercamiento a las concepciones estéticas y políticas que en ella se enfrentaron. Tales investigaciones tratan el tema en forma global, es decir, como tendencias discursivas. A diferencia de ello, el presente trabajo se enfoca en un análisis individualizado de cada uno de los textos que conforman la polémica de 1894 para así determinar, además de los ejes estéticos y políticos de fondo, las estrategias discursivas allí empleadas. En consecuencia, el corpus está compuesto por una carta de Antonio Zambrana, la reseña "Hojarasca" de Carlos Gagini, una carta de Fernández Guardia, la respuesta de Gagini y un artículo de Benjamín de Céspedes.

\section{La voz del Maestro}

Toda la polémica se abre con una reseña, fechada el 28 de mayo de 1894, que el cubano Antonio Zambrana (1894: 136-8) escribe en la revista Cuartillas.

El texto se inicia con la indicación de que se trata de una respuesta a la consulta que los editores de la revista le han hecho sobre trabajos literarios. Este incipit define el estatus discursivo y programa su descodificación: el lector contemporáneo se enfrentaría a una instancia privilegiada de autoridad, la figura del Maestro que dicta cátedra y ante la cual los discípulos escuchan y asienten. Los editores de Cuartillas no dudan en reconocer el magisterio de Zambrana, a quien califican de "propagandista de la teoría sana" que con "su mano maestra nos señala el buen camino y sus palabras nos alientan para seguirlo" (Notas 1894: 160) ${ }^{1}$. Es indiscutible que este abogado cubano ejerció, durante su estancia en Costa Rica, entre 1876 y 1906, un rol de mentor de la élite letrada liberal mediante su activa participación en dos sectores claves dentro de las estructuras del poder: el derecho y la educación ${ }^{2}$.

Como Maestro -y jurista- que es, Zambrana se ocupa de establecer las reglas que deben regir la escritura literaria: "sentir de veras la inspiración directa de su asunto" lo que "equivale á condenar las imitaciones de brujería francesa y todos los convencionalismos literarios que ahora se encuentran tan de moda". De modo tal que su regla se traduce en la reprobación del impresionismo, el parnasianismo, el naturalismo, para luego pedir a los escritores "ser ustedes mismos", lo que dentro de sus concepciones estéticas significa aceptar el neoclasicismo ${ }^{3}$.

Tras tal alarde de autoridad, Zambrana alaba a Fernández Guardia por Hojarasca, texto que, según él, no estaría afectado por los males del afrancesamiento; sin embargo, de inmediato desliza una crítica contra sus tendencias exotizantes: "Y aún así y todo, regañaría yo á Ricardo, si me atreviera, por que no mira y explota bastante lo que tiene más cerca ó á su alrededor, sino que prefiere irse lejos". Los recursos retóricos empleados a lo largo del texto, gracias a una cadena de elogios, disfrazan la condena total de Hojarasca; sin embargo, el perfecit, ya no dirigido a 
Fernández Guardia sino en tono de admonición general, aclara que los relatos de éste han violentado la regla básica de la escritura literaria -hablar únicamente de aquello que es referente inmediato- y, por lo tanto, no escapan a la descalificación por no responder a la ética realista y nacionalista. De este modo, incipit y perfecit se armonizan en un mandato: el Maestro ordena escribir sobre la realidad costarricense "sin recalentarlo ni ponerle salsas de afuera".

\section{Gagini antimodernista}

En el mismo número de Cuartillas, Gagini publica, bajo el seudónimo Amer, un breve artículo sobre Hojarasca, que tradicionalmente ha sido considerado como el texto iniciador de la polémica (1894: 139-40); luego, en otro artículo aparecido en La República el 29 de junio de $1894^{4}$, reiteraría idénticos argumentos. En ambos textos, sobre todo en el primero, se definen, con mucha mayor claridad de la empleada por Zambrana, las tres críticas fundamentales que los realistas dirigirían contra los códigos literarios modernistas defendidos por Fernández Guardia.

Tras las alabanzas de rigor, Gagini expone, en primer lugar, que los cuentos de Hojarasca "adolecen de los defectos inherentes a todo primer libro, resabios hijos de la inexperiencia y que desaparecen con la práctica". Esta es la matriz de uno de los cuestionamientos que en todo el mundo hispánico se le hizo a los escritores modernistas: el ser jóvenes. El tema del escritor-niño es una estrategia deslegitimadora mediante la cual la crítica negó la independencia y originalidad del escritor al considerar su obra como resultado de la inexperiencia y la inmadurez. Desde esta perspectiva, este mismo candor juvenil sería el que propiciaría el deslumbramiento del escritor ante la "pedrería" francesa y su abandono de los temas nacionales, tal y como lo expresa Gagini: "Lo lejano, lo misterioso, lo nuevo, eso es lo que atrae a las imaginaciones juveniles". Como contrapartida, el crítico ocuparía una posición de superioridad, como la de un padre de familia, desde la cual tendría la autoridad de guiar y corregir los desvíos modernistas (Rojas 1995: 94-7).

En segundo término, Gagini cuestiona "la elocución, á veces descuidada y no muy pura”. La crítica tradicional ha calificado a Fernández Guardia de "academicista” por su menosprecio hacia el empleo de costarriqueñismos, pero es evidente que el término es también aplicable a Gagini por su defensa de la pureza del lenguaje. Incluso, en esta primera fase de la polémica -en la que no se llega a discutir la legitimidad o no de la inclusión literaria del lenguaje concho, tema que sólo se desarrolla en la polémica de $1900^{5}$-, es más bien Fernández Guardia quien recibe los reproches academicistas de Gagini. Este último se rebela contra la sobrecarga ornamental del léxico modernista y su búsqueda formal que privilegian la expresión sobre el contenido (Yurkievich 1976: 21). Así, su queja contra la "enojosa enumeración botánica de las tres primeras páginas de El Derviche" se puede entender como una preferencia por un lenguaje especular, claro, eficaz, sometido a las reglas y necesidades de una comunicación eminentemente referencial. El neologismo "abracadabrante", acuñado por Fernández Guardia para referirse a quienes sostienen una tesis referencialista de la literatura, es criticado por Gagini en lo que constituye una muestra de su inconformidad, y de paso de su academicismo, ante las libertades lingüísticas modernistas; Gagini aprovecha que Fernández Guardia había citado a Salvador Rueda y a Darío en su defensa y elabora 
neologismos onomásticos irónicos con los que se burla de este proceso creativo, al que son especialmente afectos los modernistas: "(aunque no sé a ciencia cierta qué quiso usted decir con ese vocablo salvadorruelesco o rubendaríaco)".

Por último, y esta es la crítica famosa con la que tradicionalmente se ha identificado la polémica, Gagini plantea que la "elección de asuntos" en Hojarasca es incorrecta, puesto que no trata "sujetos nacionales" ("nuestro pueblo y sus costumbres") sino "argumentos gastados" y escenas que no se identifican de manera folklórica con la realidad costarricense. Pero la justificación de esta crítica la centra Gagini en que tal actitud exotista impide crear "obras literarias interesantísimas y llenas de novedad para los extranjeros". Pareciera paradójico que la censura del exotismo literario se asiente sobre razones igualmente exóticas, pero lo que subyace es la ambivalencia fundamental del discurso liberal nacionalista que duda entre la fascinación hacia el otro exterior como modelo y el temor ante su intromisión, en este caso desde la palabra modernista ${ }^{6}$, cosmopolita y autónoma. Esta es la construcción de la propia identidad oligárquica basada en la definición del otro (Fumero 1998: 98): el otro interior, ocultado y negado, y el otro exterior admirado y temido.

Dentro de este proceso identitario, se encuentra implícita la concepción de la literatura como discurso ancilar, es decir, sometido a los requerimientos, en este caso, de un proyecto político de constitución del estado nacional. La invención de la nación en cuanto comunidad política imaginada, soberana y limitada (Anderson 1991: 6) es la gran tarea ideológica de la élite liberal de finales del siglo XIX. La difusión del aparato educativo fue el medio que permitió la creación de un imaginario nacional regido por los valores del patriotismo, el capitalismo y la ciencia y que permitió la inclusión subordinada de campesinos y artesanos y su sometimiento -no siempre dócil- a los intereses de los sectores oligárquicos ${ }^{7}$. En este proceso de creación y sometimiento a lazos comunitarios organizados desde la asimetría social, la literatura cumple, junto con otros discursos no literarios ${ }^{8}$, la función de articular frente al otro exterior una imagen homogénea y armoniosa de la nación.

En íntima relación con esta concepción utilitaria de la literatura, se sientan las bases del verosímil literario que imperaría en Costa Rica durante décadas: la literatura como trasunto fiel de la realidad. Una muestra de lo ampliamente aceptado que fue tal verosímil desde esa época lo constituye el hecho de que los editores de Cuartillas defendieron a Fernández Guardia de las críticas de Gagini al argumentar que aquel estaba autorizado a escribir sobre Europa, pues la conocía personalmente (Notas 1894: 161). Esto evidencia que inclusive la defensa del modernismo podía asumir también el verosímil referencialista, lo cual, en razón de constituir una flagrante contradicción de principio, hace patente la incomprensión predominante durante esta fase inicial de la literatura costarricense en cuanto a los postulados modernistas básicos. Sería hasta la década de 1900, bajo el impulso de Brenes Mesén, José María Zeledón y otros, que el modernismo tomaría verdadera fuerza en el país.

\section{El joven modernista}

La respuesta de Fernández Guardia no se hizo esperar: en El Heraldo de Costa Rica del 24 de junio de 1894 apareció su defensa bajo la forma de una carta dirigida a Pío Víquez, director de ese periódico (Segura Montero 1995: 21-5). 
En primera instancia, debe remarcarse el hecho de que Fernández Guardia, dejando de lado las revistas literarias, traslada la polémica a los diarios (a partir de ese momento, los restantes textos de la discusión se publicarían en periódicos). Según Ovares, quien sigue los conceptos de Benedict Anderson sobre la invención de la nación, tanto periódicos como revistas literarias cumplen una labor similar en cuanto a la constitución de una comunidad de lectores que comparten una simultaneidad temporal en la que hechos independientes convergen en un mismo espacio. Así, estas publicaciones fortalecen una idea moderna del tiempo, "tiempo homogéneo y vacío, atravesado por la simultaneidad y la coincidencia temporal y medido por el calendario y el reloj, por lo que 'every essential modern conception is based on a conception of meanwhile"” (Ovares 1994: 93-4). Por ello, afirma esta autora, las polémicas entre modernistas y criollistas se dieron indistintamente en periódicos y revistas (100).

En desacuerdo con lo sostenido por Ovares, no parece que el abandono del espacio de la revista literaria y el planteamiento de la polémica en el de los periódicos sea gratuito e indiferenciado. Por el contrario, se pueden adelantar diversas circunstancias que habrían justificado tal cambio. En primer lugar, Fernández Guardia no puede responder a las críticas de Zambrana y Gagini en el mismo espacio editorial (Cuartillas) puesto que esta revista no circula más. Esto plantea una de las ventajas de la publicación periódica de cara a las revistas literarias: la regularidad de aquella frente al carácter efímero de estas. A ello se debe sumar que, por tratarse de una polémica, Fernández Guardia buscaría publicar con celeridad su defensa, lo cual no podía ser satisfecho por el inestable circuito de circulación de las revistas literarias.

En segundo término, debe considerarse la máxima importancia concedida por los polemistas al tema discutido. Para los nacionalistas, lo que está en juego trasciende lo estrictamente literario; su concepción de la literatura como lenguaje ancilar, esto es, como espacio discursivo al servicio del proyecto político de definición de la nacionalidad costarricense, les hace aceptar el traslado de la polémica a los diarios que, además de contar con un público receptor más amplio que el de las revistas literarias, "son altamente apreciados gracias a su utilidad y su cercanía a la vida diaria” (Ovares 1994: 97). Periódicos y revistas se diferencian en cuanto a su orden de prioridades, que en los periódicos privilegia las "actualidades" y subordina a ellas la crítica literaria, la reflexión política, la información sobre artes y ciencias, mientras que en las revistas se invierte para dar el puesto preponderante a la literatura, ciencia y arte en tanto que las "actualidades" pasan a un segundo término (Ovares 1994: 100-1). En suma, para estos hombres, para quienes la literatura no es su dedicación exclusiva y ni siquiera esencial, el periódico es el medio idóneo para determinar los alcances y las posibilidades de un discurso que no es autónomo y que debe estar subordinado a la conflictiva definición de una identidad nacional tanto para el consumo interno como para su exportación.

Un aspecto que resalta es el hecho de que Fernández Guardia polemiza directamente con Gagini, en tanto que ni siquiera menciona a Zambrana, quien había planteado en lo básico idénticas objeciones a su discurso modernista. Dos circunstancias son determinantes en tal definición de las fuerzas en conflicto: la estrategia retórica de Zambrana disfrazó de elogio su desacuerdo de fondo; y, fundamentalmente, la posición de autoridad de Zambrana y el respeto que le rendía la élite letrada disuadieron a Fernández Guardia de enfrentarse a él en una controversia abierta y violenta.

Aún no se ha prestado la suficiente atención al conflicto generacional que asoma tras el literario, acaso por la similitud de edades entre Gagini (29 años) y Fernández Guardia (27 
años) en el momento de la polémica. Sin embargo, el choque generacional está presente: el modernismo era visto como el resultado de la rebeldía y la inexperiencia de una juventud díscola y desorientada. Fernández Guardia sale también al paso del argumento que reduce sus características escriturales modernistas a la condición de moda juvenil. Para ello sostiene que "Estoy seguro de que si a Miguel Angel le hubiese ocurrido hacer una estatua del arte encadenado, lo hubiera representado en figura de un viejo decrépito y harapiento" (Segura Montero 1995: 23). En esta metáfora, la imagen del arte encadenado simboliza los códigos estéticos realistas: el realismo se encuentra sujeto o cautivo de lo referencial, es decir, limitado por las estrechas posibilidades de la reproducción mimética de la realidad; asimismo, el arte realista es ligado, de manera disfórica, a la vejez y la decadencia. El modernismo se concibe a sí mismo como una liberación respecto de lo viejo, entendido como la tradición literaria española de corte realista (Rojas 1995: 97), de manera tal que Fernández Guardia invierte la desvalorización del epíteto "juvenil" y lo reivindica como característica renovadora y productiva en su escritura.

En lo fundamental, en la defensa de Fernández Guardia es posible discernir dos ejes estrechamente vinculados entre sí: la tesis de la pobreza de lo costarricense como generador de sensaciones estéticas y la de la libertad del artista al elegir sus temas.

Históricamente, como se analizó en un inicio, la crítica literaria se enfocó en la apasionada denuncia que hizo Fernández Guardia de lo costarricense como incapaz de producir sensaciones estéticas. Su dicho de que "con una india de Pacaca sólo se puede hacer otra india de Pacaca" ha sido convertido en la muestra más famosa de los extremos de enajenación a los que puede llegar un intelectual europeizado?.

Tales argumentos, con los que se descalifica y sataniza la posición de Fernández Guardia, representan una visión maniquea, simplista, de lo que es una muy compleja trama discursiva en torno al circuito de producción y recepción de los textos literarios. De acuerdo con Jauss, la distancia estética es la que existe entre el horizonte de expectativas presente en una comunidad de lectores y la aparición de un nuevo texto. Tal distancia se concreta históricamente en las reacciones del público y de la crítica: “éxito espontáneo, rechazo o escandalización; asentimiento aislado; comprensión paulatina o retardada" y puede llegar a generar un cambio en el horizonte de expectativas debido a que niega las experiencias familiares o a que concientiza sobre experiencias que se manifiestan por primera vez (Jauss 1993b: 57). En el siglo XIX, ese horizonte de expectativas se entrelazaba con un paradigma literario nacido a partir de la revolución literaria romántica al que Jauss denomina historicismo y que representaba las aspiraciones de unidad nacionalista. De acuerdo con este paradigma, la interrelación entre las manifestaciones literarias expresaría la individualidad de cada nación y la literatura sería “el máximo medio en el que lo nacional podía llegar a sí mismo” (Jauss 1993: 24-5).

De conformidad con lo anterior, puede comprenderse que la casi unánime repulsa que durante un siglo acompañó las palabras de Fernández Guardia proviene de que estas atentan contra el horizonte de expectativas del por entonces incipiente imaginario literario costarricense, el cual se encontraba fundido con el sentimiento de pertenencia a la imaginada comunidad nacional. Cuando Fernández Guardia dice que "nuestro pueblo es sandio, sin gracia alguna, desprovisto de toda poesía y originalidad que puedan dar nacimiento siquiera a una pobre sensación artística" (Segura Montero 1995: 24-5), transgrede tanto el canon estético vigente como la ética nacionalista, que se han conjuntado para producir una ética-estética que postula el realismo y el nacionalismo como sus valores máximos. 
La censura a priori del europeísmo de Fernández Guardia ha invisibilizado las implicaciones de su repudio hacia el medio costarricense, que en lo fundamental son dos: a) el rechazo de la estética referencialista que obliga a escribir sobre la realidad inmediata y que desautoriza todo discurso que se aleje de ella; y b) un esteticismo exacerbado que considera que sólo lo intrínsecamente bello (evidentemente definido desde cánones eurocéntricos) puede y debe ser objeto de tratamiento artístico. En consecuencia, desde esta perspectiva, Fernández Guardia se muestra no como un simple aristócrata europeizado, sino como un escritor consecuente con su credo modernista de abandono del realismo especular y de adopción del exotismo, ambos procedimientos como afirmación de la autonomía poética ${ }^{10}$, y que rinde culto a la belleza en cuanto rechazo del cientificismo positivista y del mercantilismo burgués ${ }^{11}$. En suma, la estética que preconiza es elitista y revolucionaria a la vez, por ello plenamente modernista, y se enfrenta con el horizonte de expectativas realista y el paradigma literario historicista imperantes.

El apasionado alegato que hace Fernández Guardia en favor de la libertad del escritor en cuanto a la escogencia de temas para sus textos es lo que ocupa mayor espacio en su carta. Pone de ejemplo la vena irónica de Pío Víquez, inserta una cita de Salvador Rueda, alude a Víctor Hugo, Bizet, Merimée y Darío, siempre para demostrar que la inspiración del artista debe fluir libremente sin que se le impongan reglas ni restricciones. En esta libertad del escritor radica una reivindicación de la autonomía del arte ante la intromisión de otras esferas del conocimiento, lo cual es una característica muy propia del modernismo. En este caso en particular, la argumentación de Fernández Guardia se encamina a demostrar que la literatura no debe supeditarse, como lo pretenden los nacionalistas, a las necesidades ideológicas del proyecto político liberal de invención de la nación. Para ello produce un rebajamiento de la comunidad imaginada como nación y de algunos de sus mitemas ${ }^{12}$ fundantes. Fernández Guardia da un trato irónico a la guerra de 1856, cuyo rescate como "Campaña Nacional” en la década de 1890 fue la base para la definición de una identidad nacional (Palmer 1992: 18298, Molina 1996: 65-6), cuando refiere la supuesta exigencia a un pintor de retratar a una "costarricense descendiente de los héroes del 56" y no a una inglesa o a una china (Segura Montero 1995: 23). Al aludir a "guatusos" y "talamanquinos", "estos señores incivilizados, aunque ciudadanos costarricenses" (Segura Montero 1995: 24), esos otros invisibilizados, desvirtúa el mito de la homogeneidad racial blanca, que constituyó una de las principales metas de los ideólogos liberales (Palmer 1995:77), y ridiculiza la pretensión de inserción dentro de la comunidad internacional en condición de nación soberana ("En estos paisecitos de América...") (Segura Montero 1995: 25).

Justamente, uno de los “crímenes" atribuidos a los modernistas por sus detractores es su automarginación de la temática nacionalista. De allí que Unamuno, acérrimo crítico de esta corriente, estimara que "el más grave cargo que habrá de hacerse algún día a esa literatura llamada, con más o menos propiedad, modernista o decadente, que ha soplado como un vendaval sobre los espíritus en América, será su neutralidad frente a la patria, su poco o ningún calor patriótico, su ignorancia de la Historia, su vaciedad liriconovelesca" (Chaves 1970: 112).

Por último, es necesario aclarar que el fuerte rechazo hacia lo popular que se encuentra en el texto de Fernández Guardia no lo distancia de sus oponente nacionalistas, sino que los aproxima entre sí. En ningún momento, Zambrana, Gagini o Briceño niegan que el pueblo costarricense sea "sandio, sin gracia alguna". El silencio de los escritores nacionalistas demuestra su tácito asentimiento hacia los postulados político-pedagógicos del discurso liberal 
finisecular, el cual acepta la grosería y vulgaridad del mundo de los campesinos y artesanos y se propone su educación, es decir, su transformación según los valores burgueses de "patriotismo, higiene, disciplina laboral, ciencia y adscripción a la ideología del progreso, en su sentido capitalista y positivista" (Molina 2001: 82). En este sentido, por lo tanto, resulta inexacto afirmar, como lo hiciera Castro Rawson (1966: 165), que los nacionalistas defienden al pueblo costarricense de los ataques europeístas de Fernández Guardia. Tanto este como los nacionalistas son elitistas y menosprecian las culturas populares: el primero en razón de un esteticismo metropolitano exacerbado y los segundos por cuanto se proponen convertir a la plebe, de tradición española y católica, mediante la educación, en un colectivo ciudadano partícipe de la lógica burguesa que rige la imaginada comunidad nacional.

Los liberales costarricenses afirmaron la posibilidad y la necesidad de literaturizar la figura del campesino sin que ello significara su propia identificación con los sujetos populares; de allí que Magón, uno de los defensores y practicantes del nacionalismo literario, pudiera ironizar sobre esos sujetos sin incurrir en contradicción alguna; como señala con toda agudeza Amoretti, “...los liberales no 'tomarían de su propio caldo', ya que la naturalización de su invención es obviamente tan sólo para los demás. De ahí el guiño de ojo que Magón hace constantemente a su lector" (2002: 139-40).

\section{La reiteración de lo dicho}

La polémica se cierra con la carta que publica Benjamín de Céspedes ${ }^{13}$ en El Heraldo de Costa Rica el $1^{\circ}$ de julio de 1894 (Segura Montero 1995: 33-7). En ella no se encuentran mayores novedades, sino que se repiten algunos de los argumentos empleados por Zambrana y Gagini para criticar el modernismo de Fernández Guardia.

En primera instancia, emplea una falacia ad aetatem (le llama "joven literato" y "novel escritor"), esto es, alega la juventud del escritor como recurso para desacreditarlo por su inexperiencia. De seguido, lo tacha de afrancesado mediante la condena de "la prosa muy untada de perfumería francesa" y "las perlas de vidrio de patente francesa o española". Además, fustiga el menosprecio de lo nacional por parte de Fernández Guardia (califica de riesgosas sus opiniones sobre el tema) y denuncia su esteticismo exacerbado al considerar que la belleza artística se puede encontrar en asuntos que no son intrínsecamente bellos, tales como la vida de pueblos como el ruso "desaseado, soez, supersticioso, servil, brutal y ebrio"). En cuanto a este último aspecto, obsérvese que, de nuevo, el discurso nacionalista acepta tácitamente la vulgaridad del pueblo costarricense al establecer un paralelismo con el ruso para defender que tanto el uno como el otro, independientemente de su carácter "soez" o "sandio", pueden ser objeto de tratamiento estético. En suma, no se defiende a las clases populares costarricenses, se defiende la posibilidad de elaborar un discurso estético que contribuya, mediante la inclusión de tales sectores, a la invención de la nacionalidad.

El mayor interés del texto de Céspedes radica en que explicita el paradigma literario historicista predominante entre la intelectualidad finisecular. Céspedes parte de la noción del genio literario como encarnación del espíritu nacional: Homero en Grecia, Shakespeare en Inglaterra, Goethe y Schiller en Alemania. "Si estos genios sobrevivieron en la historia literaria, se debe, más que todo, al carácter eminentemente nacional de sus obras, cuyas aspiraciones y empresas 
trataban ellos de encarnar en sus personajes y descripciones" (Segura Montero 1995: 35). De acuerdo con tal paradigma, la escritura es la instancia discursiva privilegiada, "el máximo medio", para la expresión de lo nacional (Jauss 1993: 62); por lo tanto, la literatura modernista, reacia a sujetarse a los estrechos límites de la escritura referencial nacionalista, vendría a ser superflua, frívola, anticívica, extranjerizante, antipatriótica y, por ello mismo, condenable.

\section{Corolario}

Sobre el modernismo ha pesado, desde el mismo momento de su nacimiento en cuanto movimiento literario, una serie de acusaciones tendientes a deslegitimarlo como producción discursiva latinoamericana. La crítica literaria de la época redujo el fenómeno modernista a un asunto de afrancesamiento, es decir, de mímesis directa de los modelos simbolistas y parnasianos en boga, y lo tachó de llevar su esteticismo hasta el amaneramiento, de destruir el castellano con una galiparla indigerible y de encastillarse en un mundo de fantasía que vuelve las espaldas a sus realidades nacionales.

Tales simplificaciones, invisibilizadoras de las complejas particularidades de cualquier corriente estética, han devenido en verdaderos estereotipos que se proyectan aún en la actualidad. En una práctica que le es común, la crítica literaria ha escamoteado su condición de discurso, es decir, de texto surgido de determinadas condiciones sociales (Trottier 1993: 38) y ha pontificado sobre un deber ser de la escritura literaria costarricense. De acuerdo con su razonamiento, la escritura realista sería la que mejor se adapta a la expresión de la nacionalidad costarricense. En realidad, el código estético realista es el que mejor responde a las necesidades del proceso de invención de la nación, pero la crítica literaria tradicional parte de la premisa de la existencia de la nación como entidad objetiva, sin llegar a intuir que esta es más bien un conjunto de prácticas discursivas y no discursivas que se articulan en un proyecto político de imposición de un consenso y de creación de un sentimiento de lealtad en torno a intereses de clase de la jerarquía social. De allí deriva la condena de Fernández Guardia por sus posiciones aristocratizantes y europeístas, al tiempo que se soslaya que la oposición de este al proyecto político de invención de la nacionalidad no es antojadiza ni superflua, sino que se asienta sobre premisas estéticas modernistas en las que privan la autonomía del arte frente a lo político, el culto a la belleza y el repudio del realismo, todo ello como manifestación de oposición al racionalismo positivista y a la lógica materialista burguesa. No se trata aquí, en consecuencia, de negar lo innegable -el eurocentrismo de Fernández Guardia-, sino de estudiarlo en su especificidad discursiva.

Por todo lo dicho, es indispensable reivindicar el modernismo como guía estética de la primera fase de la producción textual de Fernández Guardia: Hojarasca y, en alguna medida, Cuentos ticos. Este será el medio para superar las limitaciones de una crítica guiada por un imperativo ético nacionalista y así ubicar y comprender tal narrativa dentro de sus particulares condiciones históricas de producción y recepción ${ }^{14}$. 


\section{Notas}

1. Es irónico cómo los liberales finiseculares emplean las imágenes del discurso religioso: Zambrana es equiparado con Jesús, el Maestro que indica el buen camino, y, por lo tanto, quien disiente de sus enseñanzas incurre en herejía.

2. Zambrana ejerció una amplia gama de cargos públicos: Presidente de la Junta de Educación de San José, Presidente del Ateneo de Costa Rica, Presidente fundador del Colegio de Abogados de Costa Rica, catedrático de la Escuela de Derecho de la Universidad de Santo Tomás y Magistrado de la Sala de Casación (Rodríguez Morejón 1947:1-100).

3. Sobre el neoclasicismo de Zambrana, véase Barrantes (1997: 69).

4. Esta segunda carta de Gagini, reproducida por Montero (1995 :27-31), es respuesta directa al artículo de Fernández Guardia que más adelante se analizará.

5. En 1900, con motivo de una carta que Magón dirige a García Monge por la publicación de El Moto, se reinicia la polémica, centrada ahora en la posibilidad del uso literario del lenguaje concho. En esta segunda fase de la polémica, Fernández Guardia se enfrenta con Leonidas Briceño y Jenaro Cardona. Véase el corpus textual en Segura Montero (1995: 41-92) y un análisis de ella en Quesada (1986: 113-9).

6. Quesada (1998: 20) define el otro exterior como aquella voz civilizada y plena que es deseada y temida por la voz (el uno) que elabora las leyes, los límites y el orden nacional, es decir, el discurso nacional oligárquico.

7. El proyecto civilizador liberal se esforzó también por someter la vida cotidiana a un concepto temporal capitalista regido por el calendario y el reloj, al dominio de las pasiones y los vicios, a la propagación del aseo personal, la pureza racial y la moral familiar (Molina y Palmer 1997: 55).

8. En especial folletos propagandísticos que ofrecían descripciones de geografía física, climatología y estadísticas de población (Ramírez 1994: 143). Sobre el tema, véase también Molina 1995: 140.

9. Este aspecto de la producción de Fernández Guardia ha resultado sumamente incómodo hasta para sus panegiristas. Para Víctor Hugo Fernández (1978: 41), la culpa de su eurocentrismo la tuvo la formación francesa que recibió de niño: "Se dice que la primera lengua de don Ricardo fue el Francés, razón por la que nos explicamos su proceder". En otro artículo dedicado a exaltar su figura se le contrapone a los "nacionalistas" que "asumían lo propio con orgullo, sin complejos" y se le llama "europeizado": "los que veían a Europa y a Occidente como el núcleo de la civilización, encontraban y encuentran la esencia de la nacionalidad costarricense en lo extranjero" (Quesada Camacho 2000: 110).

10. "La autonomía poética parece estar en proporción directa con el alejamiento de lo real inmediato. Este alejamiento se provoca hechando (sic) mano a todos los recursos de evasión, ensoñación, extrañamiento, a lo exótico, lo esotérico, lo fantástico; se produce rompiendo con las conexiones lógicas, con la verosimilitud realista, con toda verificación extratextual; se incrementa convirtiendo al medio en mensaje estético, dotando a la forma de una absoluta hegemonía" (Yurkievich 1976: 20).

11. Dentro de las contradicciones internas del modernismo se encuentra su denuncia del embrutecedor utilitarismo burgués y su lógica del dinero, al mismo tiempo que anhela un estilo de vida "artístico" que requiere fabulosas cantidades de ese mismo dinero.

12. Por mitema se entiende "un conjunto de imágenes y representaciones que adoptan la forma de una narración mitologizante o mítica” (González Ortega 1994:81). 
13. Benjamín de Céspedes Santa Cruz (1858-1914), médico cubano exiliado en Costa Rica a raíz de su participación en un movimiento independentista en su país. Fundó el Colegio San Agustín, que más adelante se convertiría en el Liceo de Heredia (Gutiérrez y Malavassi 1992: 61).

14. Como antecedente inmediato de la polémica literaria de 1894, deben considerarse las manifestaciones que Pío Víquez y otros periodistas habían realizado, en 1893, contra el envío de obras de arte costarricenses a la exposición colombina de Chicago por considerarlas rudimentarias e imperfectas (Méndez Montero 1997: 60-2). El análisis de esos textos constituye el tema de un futuro artículo.

\section{Bibliografía}

Amer. 1894. "Hojarasca”. Cuartillas. Junio: 139-40.

Amoretti, María. 2002. Magón... la irresistible seducción del discurso. San José: Ediciones Perro Azul.

Anderson, Benedict. 1991. Imagined communities. Reflections on the Origin and Spread of Nationalism. New York: Veron.

Barba, Jaime e Irma Zeledón (eds.). 1994. Letraviva. San Salvador: Istmo Editores.

Barrantes, Ana Cecilia. 1997. Buscando las raíces del modernismo en Costa Rica: cinco acercamientos. Heredia: EUNA.

Bonilla, Abelardo. 1981. Historia de la Literatura Costarricense. San José: UACA.

Castro Rawson, Margarita. 1966. El costumbrismo en Costa Rica. San José: Editorial Costa Rica.

Chase, Alfonso. 1975. Narrativa contemporánea de Costa Rica. San José: Ministerio de Cultura, Juventud y Deportes. Tomo I.

Chaves, Julio César. 1970. Unamuno y América. Madrid: Ediciones Cultura Hispánica.

Fernández, Víctor Hugo. 1978. Ricardo Fernández Guardia. San José: Ministerio de Cultura, Juventud y Deportes.

Fumero, Patricia. 1998. “Costa Rica imaginaria. Reflexiones sobre la nación”. Revista de Ciencias Sociales. 81: 97-9.

González Ortega, Alfonso. 1994. Costa Rica, el discurso de la patria. San José: Editorial de la Universidad de Costa Rica.

Gutiérrez, Pedro Rafael y Guillermo Malavassi. 1992. Diccionario biográfico de Costa Rica. San José: Universidad Autónoma de Centro América. 
Jauss, Hans. 1993. Cambio de paradigma en la ciencia literaria. En: Rall, Dietrich (ed.), 5971.

1993b. Historia de la literatura como una provocación a la ciencia literaria. En: Rall, Dietrich (ed.), 55-8.

Méndez Montero, Reymundo. 1997. Lico Rodríguez. Escultor de imaginería religiosa. San José: EUNED.

Molina, Iván. 1995. El que quiera divertirse. Libros y sociedad en Costa Rica (1750-1914). San José: Editorial de la Universidad de Costa Rica.

1996. "Don Ricardo Jiménez en un carrusel. La cultura popular y la identidad costarricense (1880-1914)". Temas de Nuestra América. 25: 63-72.

2001. La ciudad de los monos: Roberto Brenes Mesén, los católicos heredianos y el conflicto cultural de 1907. Heredia: EUNA.

Molina, Iván y Steven Palmer (eds.). 1992. Héroes al gusto y libros de moda. Sociedad y cambio cultual en Costa Rica (1750/1900). San José: Porvenir - Plumsock Mesoamerican Studies.

1997. Historia de Costa Rica. Breve, actualizada y con ilustraciones. San José: Editorial de la Universidad de Costa Rica.

Ovares, Flora. 1994. Literatura de kiosko. Revistas literarias de Costa Rica 1890-1930. Heredia: EUNA.

Ovares, Flora et al. 1993. La casa paterna. Escritura y nación en Costa Rica. San José: Editorial de la Universidad de Costa Rica.

Palmer, Steven. 1992. Sociedad Anónima, Cultura Oficial: Inventando la Nación en Costa Rica, 1848-1900. En: Molina, Iván y Steven Palmer (eds.), 169-205.

1995. Hacia la “autoinmigración”. El nacionalismo oficial en Costa Rica 1870-1930. En: Taracena, Arturo y Piel, Jean (eds.), 75-85.

Quesada, Álvaro. 1986. La formación de la narrativa nacional costarricense. San José: Editorial de la Universidad de Costa Rica.

1998. Uno y los otros: identidad y literatura en Costa Rica 1890-1940. San José: Editorial de la Universidad de Costa Rica. 
Quesada Camacho, Juan Rafael. 2000. "Ricardo Fernández Guardia: en el cincuentenario de su muerte (1867-1950)". Revista del Archivo Nacional. Año LXIV: 109-13.

Rall, Dietrich (ed.). 1993. En busca del texto. Teoría de la recepción literaria. México: Universidad Nacional Autónoma de México.

Ramírez, Sergio. 1994. "Balcanes y volcanes”. En: Barba, Jaime e Irma Zeledón (eds.), 13392.

Rodríguez Morejón, G. 1947. Los Zambrana. Tríptico biográfico. La Habana: P. Fernández y Cía. S. en C.

Rojas, Margarita. 1995. El último baluarte del imperio. San José: Editorial Costa Rica.

Rojas, Margarita y Flora Ovares. 1995. 100 años de literatura costarricense. San José: Ediciones Farben.

Segura Montero, Alberto. 1995. La Polémica (1894-1902): el nacionalismo en literatura. San José: EUNED.

Taracena, Arturo y Jean Piel (eds.). 1995. Identidades nacionales y Estado moderno en Centroamérica. San José: Editorial de la Universidad de Costa Rica.

Trottier, Daniéle. 1993. Juego textual y profanación: análisis sociocrítico de Lázaro de Betania de Roberto Brenes Mesén. San José: Editorial de la Universidad de Costa Rica.

Valdeperas, Jorge. 1991. Para una nueva interpretación de la literatura costarricense. San José: Editorial Costa Rica.

Yurkievich, Saúl. 1976. Celebración del modernismo. Barcelona: Tusquets Editor.

Zambrana, Antonio. 1894. "Señores Redactores de 'Cuartillas””. Cuartillas. Junio: 136-8. 


\section{Anexo}

\section{Señores Redactores de "Cuartillas"}

Me siento muy favorecido por la confianza que en mí ponen ustedes al consultarme acerca de sus trabajos literarios. Desde que se iniciaron, he seguido su marcha con interés y simpatía: después del heroísmo moral, y contribuyendo, de seguro, para despertarlo y mantenerlo, el arte es el empeño que más enaltece y abrillanta la vida; su acicate de oro nos hace levantarnos sobre los horizontes de la vida vulgar; no para despreciarla, sino para verla a una luz nueva, que la transfigura y ennoblece. Cultivar las letras es cultivar, al mismo tiempo, el propio pensamiento: es atravesar los vastos campos que encierra, aspirando el aroma penetrante de flores misteriosas que sólo esperaban nuestro conjuro para abrirse; es hacer en nuestro interior un viaje lleno de sorpresas, viendo brotar inesperados manantiales, oyendo el canto de pájaros desconocidos que nos dan la canción y la elegía de nuestras secretas congojas y delicias; es, por magia adorable, transformar en pensil un erial, llenar de música algún desierto de los que llevamos en la intimidad de nuestro ser; es trabajar nuestro mármol, el mármol vario de nuestra palabra, puliendo y cincelando el trozo informe e infiltrando en la piedra la chispa sagrada de la idea, a cuyo influjo ha de palpitar como con nervios y con sangre.

$\mathrm{Y}$ a la hora en que escribo saben ustedes, por feliz experiencia, todas las dichas de la incubación maravillosa. Perseveren sin desmayo en el cultivo de esa planta que no se vende, pero que es tan dulce tener en un tiesto, aunque sea humilde, en el taller de las fatigas cotidianas.

En cuanto al criterio que debe dirigir sus tareas, no necesito mucho espacio para señalarlo. Las Musas no se dejan violentar: hay que pretender sus favores con acatamiento y con sincera reverencia. Muchas veces me han oído ustedes repetirles el consejo de un eminente crítico español: "pensar alto, sentir hondo y hablar claro": todo eso se comprende en una regla más sencilla: sentir de veras la inspiración directa de su asunto.

Por supuesto, que ello equivale a condenar todas las imitaciones de bujería francesa y todos los convencionalismos bastardos que ahora se encuentran tan de moda. Nada de ser impresionistas, ni parnasianos, ni naturalistas ni dantescos: ser ustedes mismos. Abandonar con valor, aunque eso guste a muchos, la afectación de sensaciones y de ideas que no son las propias: dejar a Coppée y a Mendes en París, y a las sultanas en Constantinopla y a las princesas chinas en el Asia: no entrar en el taller sino cuando hay un sentimiento nuestro o una idea nuestra que están ansiosos por hervir y cantar en la palabra. Esto no quiere decir, ni mucho menos, que si pensando en la India, tienen ustedes una fantasía que vuela hacia ella o que de ella les venga, no les sea lícito contársela a su público; a condición de que nazca en ustedes y no en la lectura y contagio de obra de otros, y a reserva también de que no lo tomen por manía dando a entender con su conducta que el arte para ustedes ha de ser por fuerza un bazar oriental, o algún otro almacén de esa naturaleza.

Por fortuna, se publicó aquí hace poco un libro que puedo poner por ejemplo en el asunto: no digo dechado para que no se enoje la modestia del autor. No hay sospecha de duda de que 
me refiero a la "Hojarasca" de Fernández Guardia. Nadie me quita de la cabeza que lo llamó así con intención irónica, y para aludir a los libros que están de moda, y a que no se parece. Lo primero que lo diferencia es que está escrito en español, lo que tratándose de escritores y públicos que hablan y escriben ese idioma, el cual muchas veces, es el único que conocen hasta cierto punto, no carece del todo de importancia. Después, sin excluir la fantasía, (díganlo las lindas hadas negras que salieron más tarde) Fernández Guardia no afecta ni se contorsiona, ni imita, ni sigue modas literarias, aunque no suele descuidar las del vestido. Se va a su asunto o a sus recuerdos y conversa con ellos: diálogo decente y aún aristocrático, y en que uno de los que hablan es un poeta; pero claro y sencillo, sin afeites ni postizos, y sin un solo relumbrón de piedra falsa. Y aún así y todo, regañaría yo a Ricardo, si me atreviera, por que no mira y explota bastante lo que tiene más cerca o a su alrededor, sino que prefiere irse lejos, en lo que barrunto cierto homenaje a la escuela consabida; por ahí verán ustedes si tiene para mí importancia la reglita. Su patria, su casa, su familia, sus novias, sus estudios, sus dudas, sus creencias, su historia y la de su tierra, sus "impresiones y sus ideas", en una frase: dennos ustedes eso, y sírvanlo fresco, sin recalentarlo ni ponerle salsas de fuera: ese es el arte que les aconsejo.

A. Zambrana

San José, 28 de mayo de 1894. Cuartillas. Junio: 136-138. 